\title{
Investigation on the Secondary Generation of Natural Gas Hydrates in Horizontal Wellbore Caused by Pressure Jump during the Depressurization Development of Hydrate Bearing Layers
}

\author{
Qingjun Du, ${ }^{1,2}$ Yongge Liu, ${ }^{1,2}$ Jian Hou, ${ }^{1,2,3}$ Lina Shi $\mathbb{D}^{1,2}$ Wenbin Wang, ${ }^{1,2}$ \\ and Kang Zhou ${ }^{1,2}$ \\ ${ }^{1}$ Key Laboratory of Unconventional Oil \& Gas Development (China University of Petroleum (East China)), Ministry of Education, \\ Qingdao 266580, China \\ ${ }^{2}$ School of Petroleum Engineering, China University of Petroleum (East China), Qingdao 266580, China \\ ${ }^{3}$ Laboratory for Marine Mineral Resources, Qingdao National Laboratory for Marine Science and Technology, \\ Qingdao 266237, China
}

Correspondence should be addressed to Lina Shi; shilina@upc.edu.cn

Received 1 July 2020; Revised 22 September 2020; Accepted 27 September 2020; Published 20 October 2020

Academic Editor: Wei Wei

Copyright (c) 2020 Qingjun Du et al. This is an open access article distributed under the Creative Commons Attribution License, which permits unrestricted use, distribution, and reproduction in any medium, provided the original work is properly cited.

When the depressurization development of a hydrate-bearing layer is initiated, the temperature of the near-wellbore formation quickly decreases to near the equilibrium temperature due to the dissociation of natural gas hydrate Therefore, the secondary generation of natural gas hydrates in the wellbore easily occurs if pressure jumps to a high value due to the changes of production rates or shutdown of the well. Though hydrate generation in the process of high-pressure drilling and gas and water transportation has been widely investigated, the secondary generation of natural gas hydrates caused by pressure jump during the depressurization development process is not fully understood. In this study, the multiphase pipe flow of a horizontal well, the Vyniauskas-Bishnoi generation dynamics of natural gas hydrate, and a decomposition dynamics model developed by Kim and Bishnoi are combined to build a set of horizontal well gas-liquid-solid three-phase flow models, which consider the phase transition in the wellbore and distinguished the secondary hydrate generation area in the wellbore under different temperature and pressure conditions. The results show that when the toe-end pressure is $7 \mathrm{MPa}$ and the environment temperature is $6.4^{\circ} \mathrm{C}$, the secondary hydrate generation exists in the horizontal section of the horizontal well, and the maximum hydrate flow velocity in the wellbore is $0.044 \mathrm{~m}^{3} / \mathrm{d}$. A high toe-end pressure, low environment temperature, and high gas output will result in a greater hydrate generation in the wellbore, and the wellbore pressure will have a remarkable influence on the amount generated and its range.

\section{Introduction}

Natural gas hydrate is an ice-like substance existing in highpressure and low-temperature environments and is widely distributed in deep-sea sediment and land permafrost. Its reserves are extremely large, i.e., approximately twice as much as conventional fossil energy $[1,2]$. The USA, Canada, Japan, and China have successfully carried out a trial production of natural gas hydrate reservoirs, concurrent with the gradual increase in global energy consumption and a reduc- tion in fossil energy reserves. Natural gas hydrate has been regarded as one of the most promising new energy sources during the 21st century and has received heavy attention [3-5]. Natural gas hydrate is in a solid form in a reservoir and has no flowability, and its existence requires special temperature and pressure conditions. The current method of development is to decompose the hydrate by artificially destabilizing its conditions [6-8]. The state of gas hydrate generally varies dynamically during the exploitation process. The produced natural gas can react with the residing water 
and reform hydrate. At present, the main development methods of natural gas hydrate reservoirs include depressurization, thermal activation, $\mathrm{CO}_{2}$ displacement, and chemical injection [912]. Compared to thermal activation, $\mathrm{CO}_{2}$ displacement, and chemical injection, depressurization can achieve a level of production without injecting fluid into the reservoir, which incurs the lowest development cost. Meanwhile, its technical feasibility has been proven by the successful development of the Messoyakha Gas Reservoir of the former Soviet Union; thus, depressurization has been the most studied development method in this field [13-15]. The decomposition of natural gas hydrate is an endothermic process, the reservoir temperature during the depressurization development process gradually decreases, and a secondary generation of hydrate is apt to occur in the near-wellbore area. Myshakin et al. established 2D and 3D models to simulate and analyze the rules of secondary hydrate generation and ice blockage during the depressurization development process $[16,17]$. Ruan et al. established a three-phase three-component core-scale hydrate depressurization simulation model and studied the influences of the hydrate secondary generation and permeability change on the development of depressurization [18]. Gaddipati and Anderson found that after one year of depressurization development, the secondary generation of hydrate occurs in the near-wellbore formation, and the results show an increased potential for the formation of secondary hydrate and the appearance of a lag time for the production rates as the reservoir size increases [19]. Using a horizontal or inclined well can increase the contact area between the wellbore and reservoir, and much higher decomposition and production rates of natural gas can thus be realized. Owing to the lengthy contact, the temperature near the wellbore will decrease after the decomposition of the natural gas hydrate, thus decreasing the temperature in the wellbore, which enhances the regeneration of the hydrates.

In fact, during conventional gas and water pipeline transportation and underbalanced drilling studies in the petroleum industry, it has been discovered that if the temperature and pressure conditions in the transportation pipe or drilling wellbore meet the hydrate generation condition, the hydrate will tend to gather at the pipe wall to cause a flow area. Numerous researchers have targeted the multiphase flow issue in a transportation pipe and drilling wellbore. Experimentally, Grasso et al. observed that hydrate sedimentary phenomena exist in the pipe flow and proposed three hydrate sedimentation mechanisms [20]. Joshi et al. adopted a 95-m-long pipe to study the hydrate blockage mechanism in a high water content system; the results showed that the hydrate generation process can be divided into three phases, i.e., the hydrate is evenly distributed in the aqueous phase when the hydrate content is low during the original phase, the hydrate starts to aggregate when the hydrate amount increases to a certain level, and the aggregated hydrate starts to deposit and eventually block the wellbore during the last phase [21]. Natural gas hydrates have been proposed as a means to capture the associated gas produced on offshore oil platforms. In this regard, Andersson and Gudmundsson adopted a circulation pipe experiment to study the viscosity and rheological properties of hydrate in water slurries and found that as the concentration of the hydrate increases, the viscosity of the water slurries increases [22]. Ding et al. adopted a high-pressure flow loop to observe the hydrate generation process when the gas and liquid mix and flow in the pipe; they found that the generation of hydrate has a significant influence on the flow type of the gas and liquid [23]. Nicholas et al. conducted a measurement of the adhesion force existing between the hydrate and the metal wall. The results showed that the hydrate entrained in the flow will not adhere to the metal wall, whereas the hydrate is directly generated on the pipe wall during the hydrate aggregation and thickening [24].

To investigate the mechanisms of the secondary generation of gas hydrate and flowability, studies have been conducted to build a simulation model to predict the generation of gas hydrates during the drilling process. In terms of mathematical modeling, Jassim et al. established a hydrate sedimentary model targeting a gas-dominated flowline; simulations were conducted on the hydrate particle size and hydrate sedimentary location [25]. Nicholas et al. established a hydrate sedimentation prediction model in a liquid condensate system according to the laws of the conservation of energy and mass and compared the resulting pressure and temperature curves [26]. Wang et al. studied a hydrate sedimentary model in a gas-dominated system with free water and conducted a simulation and prediction of the hydrate layer thickness distribution in a horizontal pipe [27-29].

The flow environment in a horizontal wellbore during the depressurization process of natural gas hydrate is quite different from that found in a conventional drilling wellbore [30]. Because hydrate dissociation is an endothermic process, the temperature of the near well region decreases to the equilibrium temperature quickly. At this time, if the pressure jumps to a high value due to the shutdown of the well or the adjustment of depressurization amplitude, natural gas hydrates will form in the wellbore and the following production of gas and water will be greatly hindered. Till now, the secondary generation of natural gas hydrates in horizontal wellbore caused by pressure jump during the depressurization development of hydrate-bearing layers has not been fully investigated. For this reason, the present study combines a mass variable flow in a horizontal well with the generation of natural gas hydrate and a decomposition dynamical model to establish a set of three-phase (i.e., gas, water, and hydrate) mass variable mathematical models for a horizontal well, which consider the hydrate phase transition in the wellbore, adopting a node analysis method to solve the model and conduct the example verification, which distinguishes the generation area of secondary hydrate under different temperature, pressure, and gas output conditions. The results of this study can provide a certain theoretical basis for the temperature and pressure control of a horizontal well in terms of the depressurization development of the hydrate reservoir and a hydrate prevention in the wellbore.

\section{Mathematical Model}

Figure 1 shows a schematic diagram of the depressurization development of a natural gas hydrate reservoir in a horizontal well. The water and methane produced through hydrate 


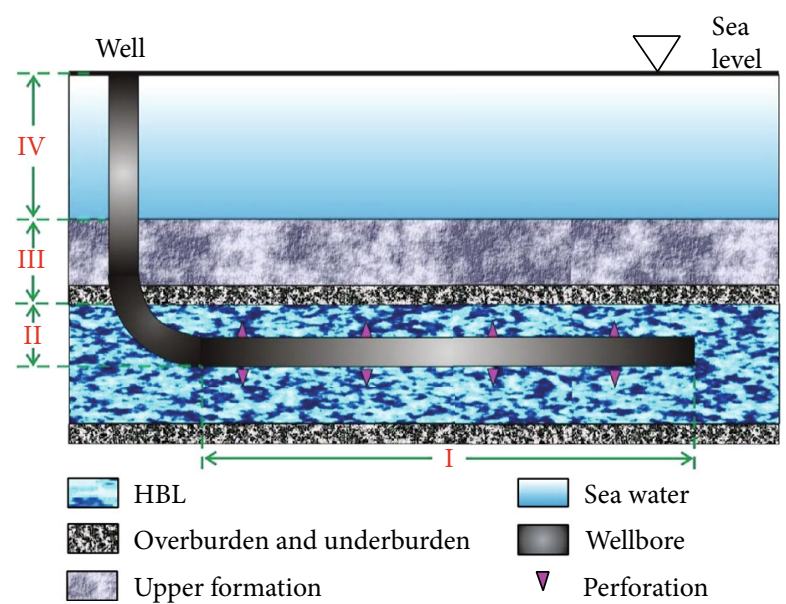

Figure 1: Natural gas hydrate reservoir horizontal well depressurization development.

decomposition will enter into a horizontal wellbore owing to the pressure difference. A hydrate generation will be triggered if the temperature and pressure condition in the wellbore meet the required conditions of the hydrate generation. If the anticoagulant and wellbore heating measures are not taken under the hydrate generating conditions, the hydrate aggregation and blockage are likely to occur by influencing the production. At this part, the mass conservation equations of the three-phase gas-water-natural gas hydrate and the momentum and energy conservation equations of the system are first established and are then combined with the Vysniauskas and Bishnoi generation dynamics model and the Kim and Bishnoi decomposition dynamical model. In addition, a three-phase mass variable mathematical model for a horizontal well considering the hydrate phase transition is established. Considering that the wellbore length is much larger than the well radius, the fluid flow in the wellbore is often seen as one-dimensional flow in the current researches and commercial software [31, 32]. In this paper, the flow is also assumed as one-dimensional, and only the flowing properties along the wellbore are investigated.

2.1. Conservation Law. Assume that the flow of each phase in a wellbore is in a stable state, for the gas and liquid phases, the changes in mass when flowing in the horizontal wellbore are mainly the amount of inflow from the hydrate reservoir to the wellbore, and the mass caused or consumed through the hydrate generation or decomposition. For the hydrate phase, because there is no inflow amount, the change in mass only equals the generation or decomposition mass. Thus, the mass conservation equations of the three phases are as follows:

$$
\left\{\begin{array}{l}
\frac{\partial\left(\rho_{g} v_{g} E_{g} A\right)}{\partial s}=q_{g}-x_{g} R_{H}, \\
\frac{\partial\left(\rho_{w} v_{w} E_{w} A\right)}{\partial s}=q_{w}-\left(1-x_{g}\right) R_{H}, \\
\frac{\partial\left(\rho_{H} v_{H} E_{H} A\right)}{\partial s}=R_{H},
\end{array}\right.
$$

where $\rho_{g}, \rho_{w}$, and $\rho_{H}$ are the densities of the gas, water, and hydrate phases $\left(\mathrm{kg} / \mathrm{m}^{3}\right) ; v_{g}, v_{w}$, and $v_{H}$ are the velocities of the gas, water, and hydrate phases $(\mathrm{m} / \mathrm{s})$; and $E_{g}, E_{w}$, and $E_{H}$ are the volume fractions of the gas, water, and hydrate phases, respectively.

Based on the momentum theorem, the momentum equations of a mathematical model for a three-phase pipe flow can be obtained as follows:

$$
\begin{aligned}
& \frac{\partial}{\partial s}\left(A E_{g} \rho_{g} v_{g}^{2}+A E_{w} \rho_{w} v_{w}{ }^{2}+A E_{H} \rho_{H} v_{H}^{2}\right) \\
& \quad=-\frac{d\left(A F_{r}\right)}{d s}-A_{g} \sin \alpha\left(E_{g} \rho_{g}+E_{w} \rho_{w}+E_{H} \rho_{H}\right),
\end{aligned}
$$

where $\alpha$ is the angle between the wellbore and the horizontal direction $\left({ }^{\circ}\right), F_{r}$ is the frictional resistance of the fluid during the wellbore flow process $\left(P_{a}\right)$, and $P$ is the wellbore pressure $\left(P_{a}\right)$.

The energy change in the fluid for each phase during the wellbore flow process mainly includes the heat carried by the injecting gas and water, the heat exchange between fluids in the wellbore and reservoir, and the heat released or absorbed through the hydrate generation and decomposition, and thus, the energy conservation equation of the system is as follows:

$$
\begin{aligned}
& \frac{\partial}{\partial s}\left[w_{g}\left(C_{g} T+\frac{1}{2} v_{g}{ }^{2}-g \cdot s \cdot \sin \alpha\right)\right. \\
& \left.\quad+w_{w}\left(C_{w} T+\frac{1}{2} v_{w}{ }^{2}-g \cdot s \cdot \sin \alpha\right)\right]=\frac{d\left(q_{g} C_{g} T_{e}+q_{w} C_{w} T_{e}\right)}{d s} \\
& \quad-2 \pi \frac{T-T_{e}}{R t}-\frac{R_{H} \Delta H_{H}}{M_{H}}
\end{aligned}
$$

where $w_{g}$ and $w_{w}$ are the mass flow of the gas and liquid phases, respectively $(\mathrm{kg} / \mathrm{s}), C_{g}$ and $C_{w}$ are the specific heat of the gas and liquid phases $\left(\mathrm{J} /\left(\mathrm{kg} .{ }^{\circ} \mathrm{C}\right)\right), T$ is the temperature in the wellbore $\left({ }^{\circ} \mathrm{C}\right), T_{e}$ is the environment temperature $\left({ }^{\circ} \mathrm{C}\right)$, $R t$ is the pipe thermal resistance, $\Delta H_{H}$ is the decomposition heat of the hydrate $(\mathrm{J} / \mathrm{mol})$, and $M_{H}$ is the average molecular weight of the natural gas hydrate $(\mathrm{kg} / \mathrm{mol})$.

2.2. Supplementary Conditions. The biggest difference between a mathematical model and a conventional gas-water variable mass flow model of a horizontal wellbore is that a mathematical model includes the natural gas hydrate generation and decomposition dynamics, whereas the aspects of the high-pressure physical properties, state equation, and flow type judgment of the gas are the same as in a conventional model. The natural gas state equation used in this paper is a P-R equation, and the flow-type judgment adopts the classical Beggs-Brill model.

As for the calculation of the hydrate decomposition rate, this paper adopts the most commonly used Kim-Bishinoi 
dynamics model, the expression of which is as follows [33]:

$$
r_{H}=A a_{s} \exp \left(\frac{\Delta E_{a}}{R T}\right) \exp \left(-\frac{a}{\Delta T^{b}}\right) \cdot P^{\gamma},
$$

where $A$ is the composite preindex constant, $A=4.554 \times$ $10^{-26} \mathrm{~cm}^{3} / \mathrm{cm}^{2} \cdot \mathrm{min} \cdot \operatorname{bar}^{\gamma} ; \Delta E_{a}$ is the activation energy, $\Delta$ $E_{a}=106204 \mathrm{~J} / \mathrm{mol} ; R$ is the gas constant, $R=8.314 \mathrm{~J} /(\mathrm{mol} \cdot \mathrm{K}$ )$; \gamma, a$, and $b$ are the test constants, where $\gamma=2.986, a=$ $0.0778 K^{b}$, and $b=2.411 ; \Delta T$ is the subcooled temperature (K), $\Delta T=T_{e q}-T ; T_{e q}$ is the phase equilibrium temperature; $P$ is the pressure $\left(\mathrm{kP}_{a}\right)$; and $a_{s}$ is the area of the gas-liquid interface, $a_{s}=67.1 \mathrm{~cm}^{2}$.

As for the calculation of the hydrate generation rate, this study adopts the Vysniauskas-Bishinoi dynamics model, the expression of which is as follows [34]:

$$
\frac{d n_{H}}{d t}=k A_{s} \exp \left(-\frac{\Delta E}{R T}\right)\left(P_{e q}-P_{g}\right),
$$

where $k$ is the decomposition rate constant, $k=1.24 \times 10^{11}$ $\mathrm{mol} /\left(\mathrm{m}^{2} \mathrm{MPa} \cdot \mathrm{s}\right) ; \Delta E$ is the hydrate decomposition activation energy, $\Delta E=78300 \mathrm{~J} / \mathrm{mol} ; R$ is the gas constant, $R=8.314 \mathrm{~J} /($ $\mathrm{mol} \cdot \mathrm{K}) ; T$ is the temperature $(\mathrm{K}) ; P_{g}$ is the pressure $(\mathrm{MPa}) ; P_{e q}$ is the pressure balance corresponding to the temperature $T(\mathrm{MPa})$; and $A_{s}$ is the total surface area of the hydrate particles $\left(\mathrm{m}^{2}\right)$. Based on the phase equilibrium line of the hydrate, the judgments of the hydrate generation, and the decomposition, the phase equilibrium line adopted by this study is the regression form proposed by Moridis in 2003 [35]:

$$
\begin{gathered}
T \geq 273.2 K \quad \ln P_{e}=\left\{\begin{array}{l}
-1.94138504464560 \times 10^{5}+3.31018213397926 \times 10^{3} T \\
-2.25540264493806 \times 10^{1} T^{2}+7.67559117787059 \times 10^{-2} T^{3}, \\
-1.30465829788791 \times 10^{-4} T^{4}+8.6065316687571 \times 10^{-8} T^{5}
\end{array}\right. \\
T \geq 273.2 K \quad \ln P_{e}=\left\{\begin{array}{l}
-4.38921173434628 \times 10^{1}+7.76302133739303 \times 10^{-1} T \\
-7.27291427030502 \times 10^{-3} T^{2}+3.85413985900724 \times 10^{-5} T^{3}, \\
-1.03669656828834 \times 10^{-7} T^{4}+1.09882180475307 \times 10^{-10} T^{5}
\end{array}\right.
\end{gathered}
$$

where $T$ is the temperature $(\mathrm{K})$ and $P_{e}$ is the pressure balance corresponding to $T(\mathrm{MPa})$.

2.3. Boundary Conditions. The inlet pressure of the wellbore, external environment temperature, horizontal well length, gas production index, and liquid production index are included as follows:

$$
\begin{gathered}
\left\{\begin{array}{l}
P(L)=P_{L}, \\
T(L)=P_{L},
\end{array}\right. \\
T_{e}=T_{e}(h), \\
\left\{\begin{array}{l}
E_{i}(L)=0 \\
v_{j}(L)=0
\end{array} \quad j=g, w, H,\right.
\end{gathered}
$$

where $h$ is the wellbore depth (m), $T_{e}$ is the environment temperature $(\mathrm{K}), T_{e}$ is the linear function of the wellbore depth (h), and $P_{L}$ and $T_{L}$ are the horizontal well toe-end pressure and temperature.

The main difference between the model in this paper and those for well drilling and gas transportation is that the gas and water will flow into the horizontal wellbore through the perforations during the development of the hydrate-bearing layer. Therefore, the fluid flow in the wellbore is variable mass flow, and the gas and liquid production indices are used to determine the inflow rate of gas and water as follows:

$$
\left\{\begin{array}{l}
J_{g}=I \\
J_{w}=J
\end{array}\right.
$$

where $I$ and $J$ are the gas production index and liquid production index and $L$ is the horizontal well length (m).

\section{Solution and Verification of Model}

3.1. Solution of Model. The node method is adopted to solve the model, which divides the horizontal well into $N$ sections, and $N+1$ nodes will be generated in total, where $i=0,1, \cdots$ , $N-1, N$. Based on the flow direction, where $i=0$ is located at the toe-end of the horizontal well, the model is then solved from the toe-end toward the heel end, deflecting the horizontal and vertical section successively. Figure 2 shows a flow chart of the calculation. The following takes any two nodes $i$ and $i+1$ in the wellbore as an example to describe the details of the calculation process. Assume that the parameters of the node $i$ are known quantities used to calculate the values of each parameter at node $i+1$.

(1) Assume that the pressure and temperature of node $i+1$ are $P_{\mathrm{i}+1}$ and $T_{i+1}$, respectively

(2) Utilize the state equation to calculate the properties of each phase at node $i+1$ and calculate the inflow 


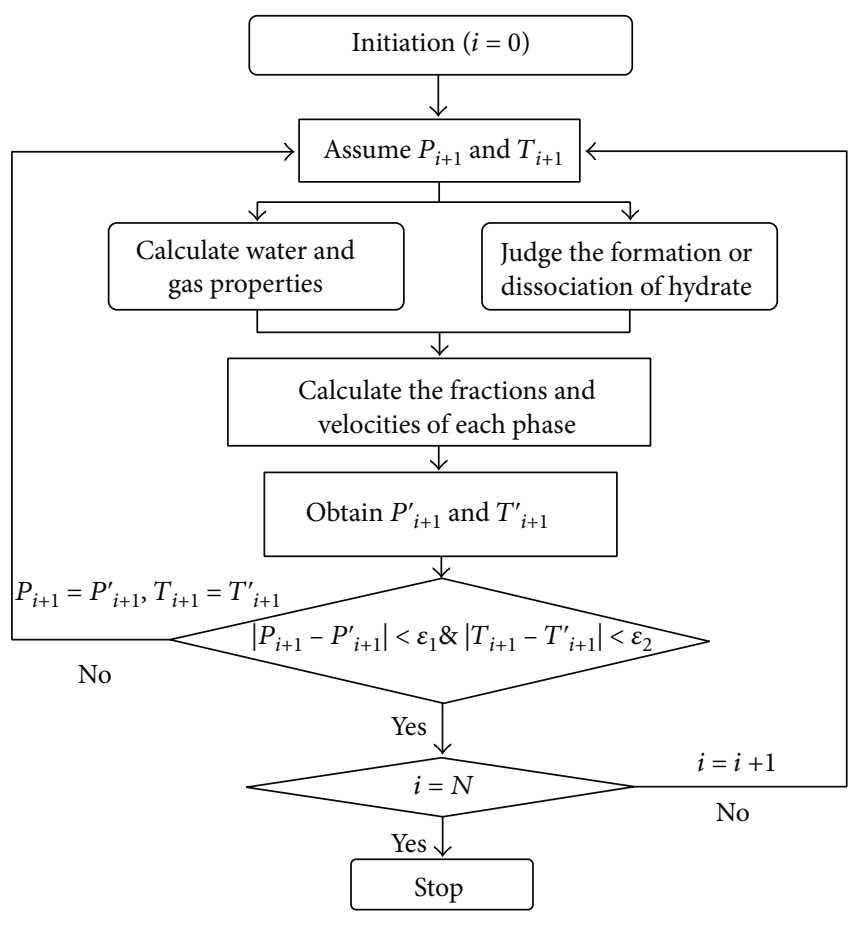

FIGURE 2: Calculation workflow.

terms of gas $q_{g, i+1}$ and water $q_{w, i+1}$ based on the gas output and liquid output indexes

(3) Base on the pressure and temperature conditions at node $i+1$ to judge whether the hydrate is generated; if the hydrate generation condition is met, the amount of hydrate generated is $R_{H, i+1}$, and the corresponding reaction heat can then be calculated. By contrast, if the hydrate decomposition condition is met, we can then judge whether the hydrate first exists. The calculation is not required if the hydrate does not exist, and if the hydrate does exist, the hydrate decomposition amount $R_{H, i+1}$ corresponding to the reaction heat can then be calculated

(4) The continuity equation is used to solve the apparent rate of each phase $v_{i+1}$

(5) The Beggs-Brill method is utilized to judge the flow type and determine the liquid holdup $E_{w j+1}$

(6) The volume fractions of the hydrate phase $E_{H j+1}$ and gas phase $E_{g j+1}$ are calculated, and the apparent rate is then utilized to solve the fluid velocities of each phase $v_{j+1}$

(7) Substitute the determined parameters into the momentum and energy equations to solve the new $P_{i+1}$ and $T_{i+1}$

(8) If the obtained pressure and temperature are within the allowable error, i.e., $\left|P_{i+1}-P_{i+1}\right|<\varepsilon_{1}, \mid T_{i+1}-$ $T_{i+1} \mid<\varepsilon_{2}$, then stop calculating the $i+1$ node; otherwise, return to step (1) to reestimate until the condition becomes true

(9) Judge whether the $i+1$ node is the last node; if not, take the parameters of $i+1$ as the known conditions for the calculation of the next node and repeat the above steps. The entire calculation of the wellbore is then complete, and the calculation is finished

(10) The parameters of all nodes in the wellbore can be calculated through the above steps

3.2. Model Verification. No detailed measurement data of the fluids in the wellbore of a natural gas hydrate reservoir with a recent trial production were available, and thus, the model verification in this study is simply for a vertical wellbore gas-liquid two-phase flow mode. The measured data in 14 actual water-and-gas producing wells in a Chinese gas field are shown in Table 1 [36]. In this study, a wellbore gas-liquid two-phase flow model was established, as described in Section 2.1, to calculate the flowing bottom-hole pressures of the 14 wells. We then compared them with the measured data, as shown in Figure 3. According to Figure 3, the relative error between the calculation results of the model established by this study and the measured data is between $0.6 \%$ and $8.4 \%$, which means that the goodness of fit is generally high, and thus, the model established through this study is reliable.

The model in this paper is verified with field data from the well testing operations on a deepwater gas well: $\mathrm{M}-3$, see refer [37]. The temperature profile along the wellbore is calculated. The ambient temperature profile is the same as in the reference. The calculated data and the measured data are shown in Figure 4. It shows that the calculated data is consistent with the testing temperature.

\section{Results and Discussions}

4.1. Temperature-Pressure Distribution and Hydrate Generation in Wellbore. Taking the basic information of the natural gas hydrate reservoir of the Shenhu Sea area of the South China Sea as a reference to conduct a parameter selection, the main parameters are as shown in Table 2 [38-41]. We assume the original pressure and temperature of a hydrate reservoir to be $10 \mathrm{MPa}$ and $11^{\circ} \mathrm{C}$, respectively. During the depressurization development process, excessive depressurization will readily lead to a fast air and water flow and the production of sand; therefore, the depressurizing range will generally not exceed $50 \%$ [42]. The depressurization range of a horizontal well is selected to be $5 \mathrm{MPa}$, which means that the horizontal well produces a pressure of $5 \mathrm{MPa}$ at a flowing bottom hole. Based on the hydrate phase equilibrium line, which was regressed by Moridis, the hydrate phase equilibrium temperature corresponding to $5 \mathrm{MPa}$ is approximately $6.4^{\circ} \mathrm{C}$; considering that the depressurization will first lead to a fast hydrate decomposition in the near-wellbore area, the temperature of the near-wellbore formation will decrease to near the equilibrium temperature. At this moment, if the pressures of the wellbore and near-wellbore 
TABLE 1: Measured data in gas wells.

\begin{tabular}{|c|c|c|c|c|c|c|c|}
\hline $\begin{array}{l}\text { Well } \\
\text { no. }\end{array}$ & $\begin{array}{l}\text { Well } \\
\text { depth }\end{array}$ & $\begin{array}{c}\text { Gas output, } 10^{4} \\
\mathrm{~m}^{3} / \mathrm{d}\end{array}$ & $\begin{array}{c}\text { Water output, } \\
\mathrm{m}^{3} / \mathrm{d}\end{array}$ & $\begin{array}{c}\text { Wellhead } \\
\text { temperature, }{ }^{\circ} \mathrm{C}\end{array}$ & $\begin{array}{l}\text { Well-bottom } \\
\text { temperature, }{ }^{\circ} \mathrm{C}\end{array}$ & $\begin{array}{c}\text { Wellhead } \\
\text { pressure, } \mathrm{MPa}\end{array}$ & $\begin{array}{l}\text { Well-bottom } \\
\text { pressure, MPa }\end{array}$ \\
\hline 1 & 3260 & 5.3 & 15.7 & 34 & 106.5 & 20.402 & 27.704 \\
\hline 2 & 3260 & 4.3 & 7 & 33 & 106 & 24.088 & 32.234 \\
\hline 3 & 3260 & 3 & 3.5 & 32 & 108 & 30.137 & 39.195 \\
\hline 4 & 2520 & 6.5 & 48 & 43 & 89 & 7.436 & 13.077 \\
\hline 5 & 2520 & 5.2 & 33 & 41 & 96 & 7.482 & 13.164 \\
\hline 6 & 2520 & 4 & 29 & 40 & 99 & 7.301 & 13.122 \\
\hline 7 & 2520 & 3.5 & 38 & 39 & 98 & 7.012 & 13.155 \\
\hline 8 & 2330 & 2.4 & 50 & 35 & 85 & 9.002 & 17.363 \\
\hline 9 & 2330 & 2 & 45 & 35 & 84 & 8.679 & 17.597 \\
\hline 10 & 2800 & 2 & 35 & 35 & 100 & 4.989 & 11.454 \\
\hline 11 & 2800 & 1 & 11.3 & 35 & 97 & 8.367 & 14.185 \\
\hline 12 & 3260 & 4.5 & 12 & 24 & 106 & 16.392 & 23.911 \\
\hline 13 & 2860 & 2.5 & 49 & 31 & 107.6 & 4.394 & 10.592 \\
\hline 14 & 2800 & 2 & 33 & 30 & 101.9 & 6.433 & 12.024 \\
\hline
\end{tabular}

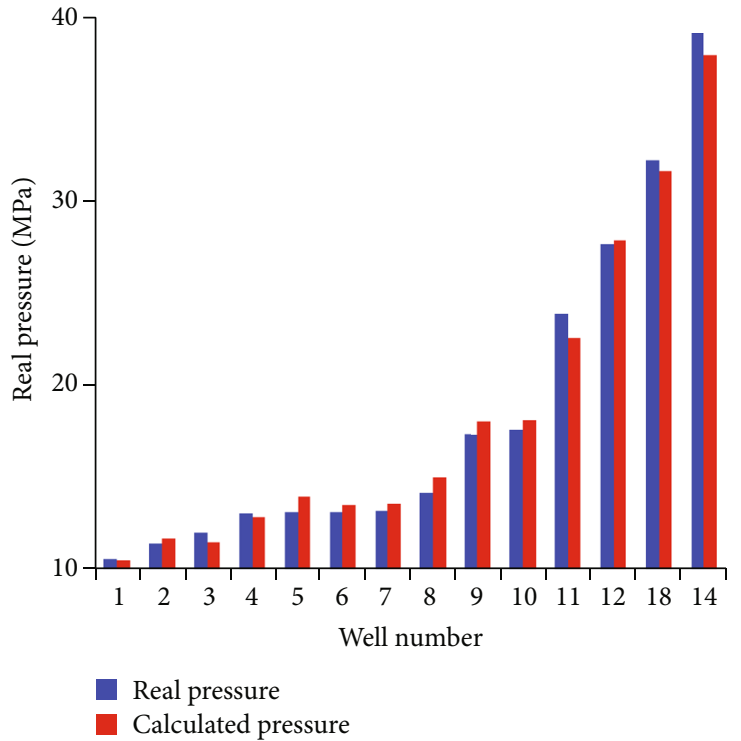

(a) Calculated pressure and measured pressure

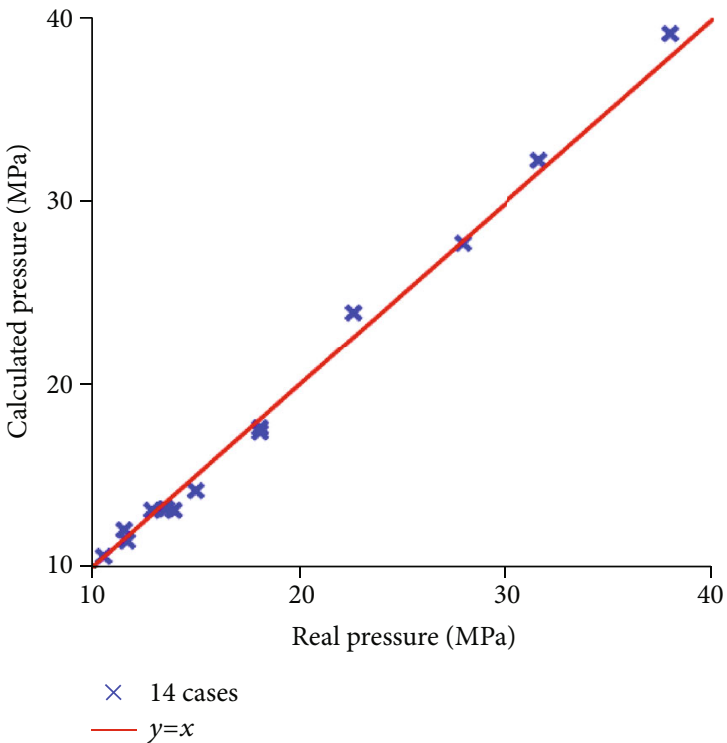

(b) Deviation

FIGURE 3: Comparison between calculated results and measured data of flowing bottom-hole pressure.

formation increase owing to a change in production and other factors, a secondary hydrate generation will easily occur in the near-wellbore formation and wellbore. Assume that the toe-end pressure increases to $7 \mathrm{MPa}$, the differential pressure of the production is $2 \mathrm{MPa}$, and thus, the pressure of the near-wellbore formation is $9 \mathrm{MPa}$.

Figure 5 shows the original temperature and pressure distribution along with the wellbore formation. The original temperature and pressure curves of the formation can be divided into four parts: Section I is the horizontal section of a horizontal well; the formation pressure in this section decreases to $9 \mathrm{MPa}$ owing to the depressurization development, and the pressure in the near-wellbore formation decreases to approximately $6.4^{\circ} \mathrm{C}$ owing to the endothermic decomposition of the near-wellbore hydrate. Section II is the hydrate layer section; the vertical deep span of this section is $30 \mathrm{~m}$, and the wellbore length in this section is approximately $80 \mathrm{~m}$ owing to the deflecting section. According to the radial flow principle, the formation temperature and pressure will gradually restore to the original formation temperature and pressure in a logarithmic form as the vertical distance between this section and the horizontal well increases. Section III is the original formation section, and the temperature and pressure in this 


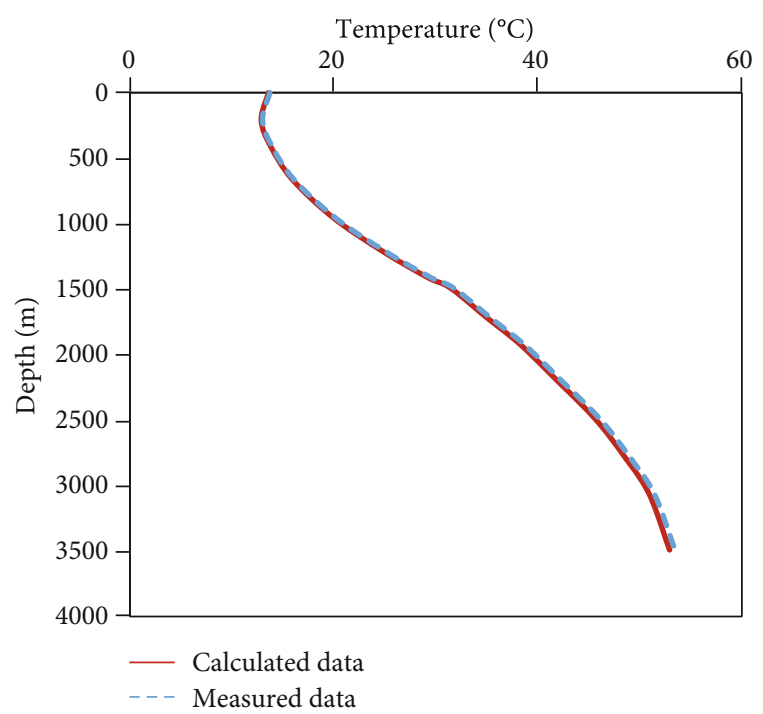

Figure 4: Comparison between the calculated temperature and measured temperature (M-3 well: gas production rate $=30 \times 10^{4}$ $\mathrm{m}^{3} / \mathrm{d}$; water flow rate $=10 \mathrm{~m}^{3} / \mathrm{d}$ ).

section are the temperature and pressure of the original formation, where the temperature gradually decreases as the depth decreases. When the flow reaches the bottom of the ocean, the temperature is $5^{\circ} \mathrm{C}$ and the pressure is $8 \mathrm{MPa}$. Section IV is the seawater section, and the temperature and pressure in this section increase linearly as the well length increases. When it finally reaches the ground, the temperature is $25^{\circ} \mathrm{C}$, whereas the pressure is $0.1 \mathrm{MPa}$.

Figure 6 shows the temperature and pressure distribution in the wellbore. It should be noted that the dotted line in Figure 6(b) denotes the equilibrium temperature at the corresponding pressure in the wellbore. Figure 7 shows the gas and water output profiles of the horizontal section at the corresponding standard ground temperature and pressure, and the hydrate flow velocity curve in the wellbore. As indicated in Figure 6, in the horizontal section, namely, Section I, the changes in the wellbore temperature and pressure are small, mainly because the viscosities of gas and water are low and the pressure loss caused by frictional resistance is also small, whereas the pressure is mainly consumed during a lift in the inclining and vertical sections; similarly, the temperatures of the inflow gas and water are the same as the formation environment temperature; meanwhile, the influences of the heat conduction and convection can be analyzed by comparing Figures 5 and 6(b). The two changing trends of the wellbore fluid temperature and the environment temperature are consistent after the entrance of the fluid into the deflecting section. The formation temperature is higher than the wellbore fluid temperature, and thus, the fluid temperature will continually increase. However, as the depth decreases, the formation temperature continually decreases, and therefore, the wellbore fluid temperature will decrease continually and the temperature will reach the lowest point at the bottom of the sea section; after entering the seawater section, the seawater temperature increases as the depth decreases, and the wellbore fluid temperature increases continually. The shaded area in Figure $6(\mathrm{~b})$ indicates that the wellbore fluid temperature is lower than the equilibrium temperature in the wellbore section; the temperatures in Sections I-IV are lower than the equilibrium temperature, and thus, different levels of hydrate are generated. By considering Figure $7(\mathrm{~b})$ as well, the hydrate flow rates in these three sections continually increase, the hydrate generation rate is high, and the increasing amplitude of the flow rate is large when the difference between the wellbore temperature and equilibrium temperature is significant; when fluid enters Section III, the hydrate generation rate slows down and the increase in the amplitude of flow rate correspondingly decreases as the wellbore fluid temperature increases. As the fluid enters Section IV, the seawater section, and migrates upward, the wellbore fluid temperature continually increases, finally exceeding the hydrate equilibrium temperature. The hydrate in the wellbore turns from a generation to decomposition, and because the decomposition rate is much faster than the generation rate, as shown in Figure $7(\mathrm{~b})$, the hydrate flow rate will decrease rapidly until a full decomposition occurs, and the flow rate is zero. Numerically, the maximum hydrate flow rate in the wellbore is $0.044 \mathrm{~m}^{3} / \mathrm{d}$ because the diameter of the wellbore is small and the tubing volume per unit length is only $7.85 \times 10^{-3} \mathrm{~m}^{3}$. If the generated hydrate has a certain amount of pipe wall deposition, it easily causes the effective diameter of the wellbore to decrease and even block the wellbore, and thus, wellbore heating and other measures should be adopted to prevent the hydrate generation in the wellbore and ensure a smooth production. According to Figure $7(\mathrm{a})$, the wellbore pressures from the toe-end to the heel-end are slightly decreased owing to a friction resistance, and thus, the differential pressure corresponding to the toe-end is the largest. The gas and water output rates are also the greatest at this point; however, the heterogeneity of the formation is not considered in this scheme because the frictional resistance is relatively small, the difference in the inflow profile throughout the entire wellbore is relatively small, and the water and gas outputs under the ground obtained through accumulation are $1.38 \times 10^{4}$ and $91.7 \mathrm{~m}^{3} / \mathrm{d}$, respectively.

4.2. Analysis of Influencing Factors. Hydrate generation is closely related to the temperature and pressure in the wellbore. In this section, we investigate the influences of the environment temperature and wellbore pressure on the hydrate generation and inflow performance.

4.2.1. Wellbore Pressure. Each parameter is kept consistent with the basic scheme, whereas the toe-end pressure is changed to $6 \mathrm{MPa}$ (corresponding to a difference in production pressure of $3 \mathrm{MPa}$ ) and $8 \mathrm{MPa}$ (corresponding to a difference in production pressure of lower than $1 \mathrm{MPa}$ ). Figure 8 shows a comparison diagram of the on-way pressure, temperature, hydrate flow rate, total gas, and water output under different toe-end pressures. Among them, 
TABLE 2: Basic parameters.

\begin{tabular}{|c|c|c|c|}
\hline Basic parameters & Value & Basic parameters & Value \\
\hline Horizontal section length, $\mathrm{m}$ & 500 & Wellhead environment temperature, ${ }^{\circ} \mathrm{C}$ & 25 \\
\hline Submarine environment temperature, ${ }^{\circ} \mathrm{C}$ & 5 & Submarine section length, $\mathrm{m}$ & 800 \\
\hline Horizontal well burial depth, $\mathrm{m}$ & 1,000 & Deflecting section length, $\mathrm{m}$ & 150 \\
\hline Sea temperature gradient, ${ }^{\circ} \mathrm{C} / 100 \mathrm{~m}$ & -2.5 & Formation temperature gradient, ${ }^{\circ} \mathrm{C} / 100 \mathrm{~m}$ & 3 \\
\hline Gas output index, $\mathrm{kg} /(\mathrm{MPa} \cdot \mathrm{m} \cdot \mathrm{s})$ & 0.0001 & Water output index, $\mathrm{kg} /(\mathrm{MPa} \cdot \mathrm{m} \cdot \mathrm{s})$ & 0.001 \\
\hline Hydrate reservoir pressure, $\mathrm{MPa}$ & 10 & Thermal conductivity of formation, $\mathrm{W} / \mathrm{m} /{ }^{\circ} \mathrm{C}$ & 3.92 \\
\hline Radius of tubing, $\mathrm{m}$ & 0.05 & Tubing thickness, $\mathrm{m}$ & 0.01 \\
\hline Radius of casing, $\mathrm{m}$ & 0.1 & Casing thickness, $\mathrm{m}$ & 0.01 \\
\hline Radius of cement sheath, $\mathrm{m}$ & 0.15 & Cement sheath thickness, $\mathrm{m}$ & 0.05 \\
\hline Thermal conductivity of cement, $\mathrm{W} / \mathrm{m} /{ }^{\circ} \mathrm{C}$ & 19.4 & Thermal conductivity of casing and tubing, $\mathrm{W} / \mathrm{m} /{ }^{\circ} \mathrm{C}$ & 45 \\
\hline Hydrate formation rate, mole/(MPa.s.m²) & $2.9 \times 10^{3}$ & Hydrate dissociation rate, mole/(Pa.s.m $\left.{ }^{2}\right)$ & $1.24 \times 10^{11}$ \\
\hline Activation energy, $\mathrm{J} / \mathrm{mole}$ & 81084.2 & Reaction enthalpy, J/mole & 51858 \\
\hline
\end{tabular}

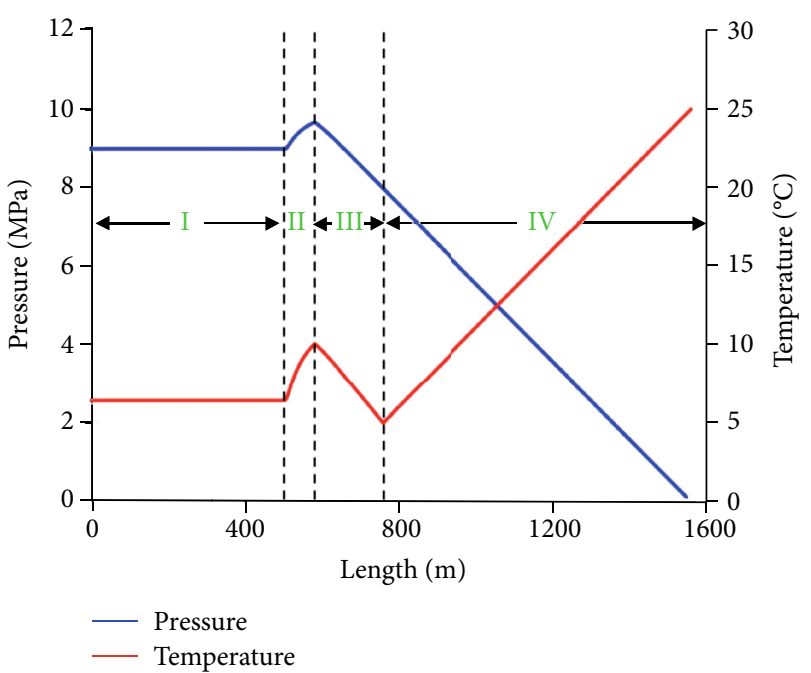

FIGURE 5: The original temperature and pressure distribution along with wellbore.

the dotted line in Figure 8(b) denotes the hydrate phase equilibrium temperature (EqT) of the corresponding wellbore pressure. According to Figure 8(a), the changing trends of the wellbore pressure under different toe-end pressures are the same, and the change in the differential pressure in the horizontal section is small; in addition, a decrease in the main pressure occurs in the fluid lifting of the vertical wellbore. The lower the toe-end pressure is, the lower the on-way pressure will be in the wellbore. Thus, the equilibrium temperature in Figure 8(b) corresponding to the toe-end pressure of $6 \mathrm{MPa}$ is the lowest point; the fluid temperature in the wellbore will rapidly increase to above the equilibrium temperature after the fluid enters the deflecting section. The hydrate starts to decompose at this time, as shown in Figure 8(c). The hydrate flow rate in the wellbore will rapidly decrease. When the toe-end pressures reach 7 and $8 \mathrm{MPa}$, respec- tively, owing to the relatively high hydrate phase equilibrium temperatures, the temperature will increase to above the equilibrium temperature only when the wellbore fluid reaches the wellbore of the seawater section. According to Figure $8(\mathrm{c})$, the hydrate peak flows corresponding to 6,7 , and $8 \mathrm{MPa}$ are $0.016,0.044$, and $0.085 \mathrm{~m}^{3} / \mathrm{d}$, respectively. According to the comparison results between the gas and water outputs (Figure 8(d)), the lower the wellbore pressure is, the greater the corresponding production differential pressure will be, and the larger the gas and water outputs that will occur without a change in the gas and liquid production indexes. Overall, the wellbore pressure has a significant influence on the hydrate generation and the generation area; in addition, the amount of hydrate flow in the wellbore increases as the toe-end pressure increases, and thus, the pressure in the wellbore should be closely monitored during the actual development of a hydrate reservoir to prevent hydrate generation and wellbore blockage.

4.2.2. Environment Temperature in the Horizontal Section. During the depressurization process of a horizontal well, the temperature of the near-wellbore formation continually decreases because of the hydrate endothermic decomposition. It should be noted that the toe-end pressure in this section is assumed to be $7 \mathrm{MPa}$. To simulate the hydrate generation in the wellbore under different environment temperatures, the environment temperatures of the horizontal section are set to $5.4^{\circ} \mathrm{C}, 6.4^{\circ} \mathrm{C}$, and $7.4^{\circ} \mathrm{C}$, respectively. Because the differential pressure and gas and water production indexes during production are constant, it can be seen that the pressure and gas and water inflows in the wellbore of the three schemes are basically the same. Figure 8 only compares and analyzes the temperature and amount of hydrate flow in the wellbore; at the same time, because the pressure change is small, the three schemes in Figure 9(a) only plot one hydrate phase equilibrium line corresponding to the wellbore pressure. According to Figure 9(a), the difference among the 


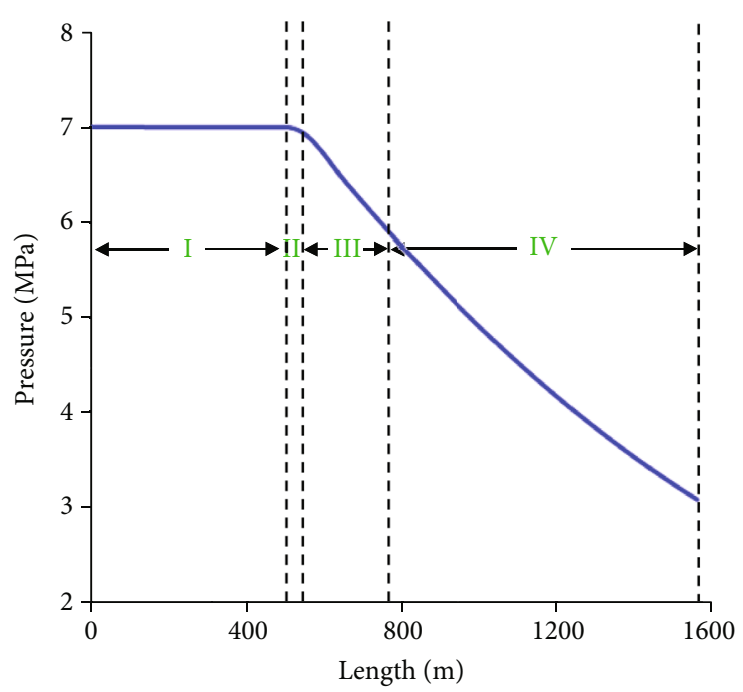

(a) Pressure distribution

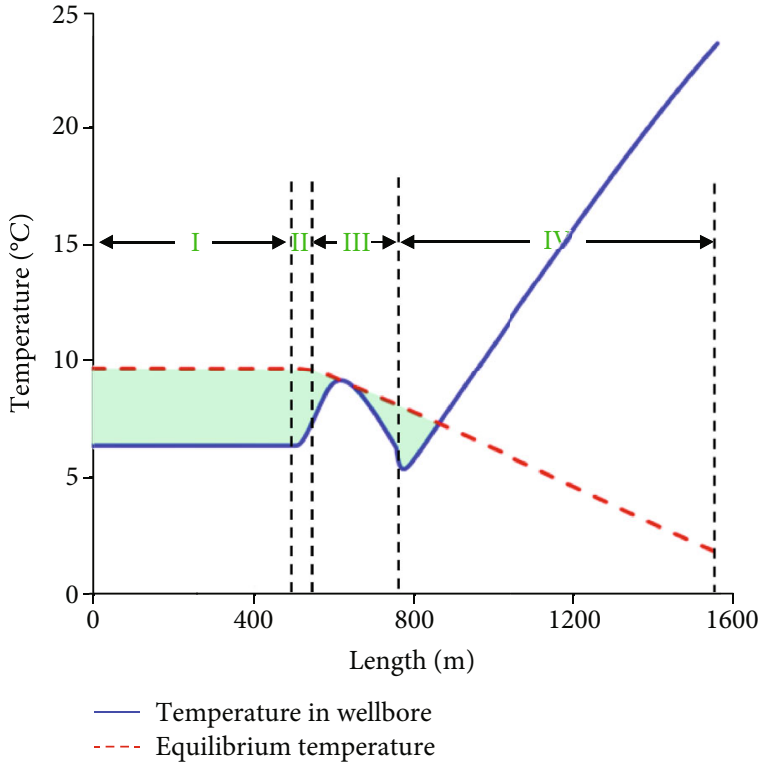

(b) Temperature distribution

FIgURE 6: Temperature and pressure distribution in the wellbore.

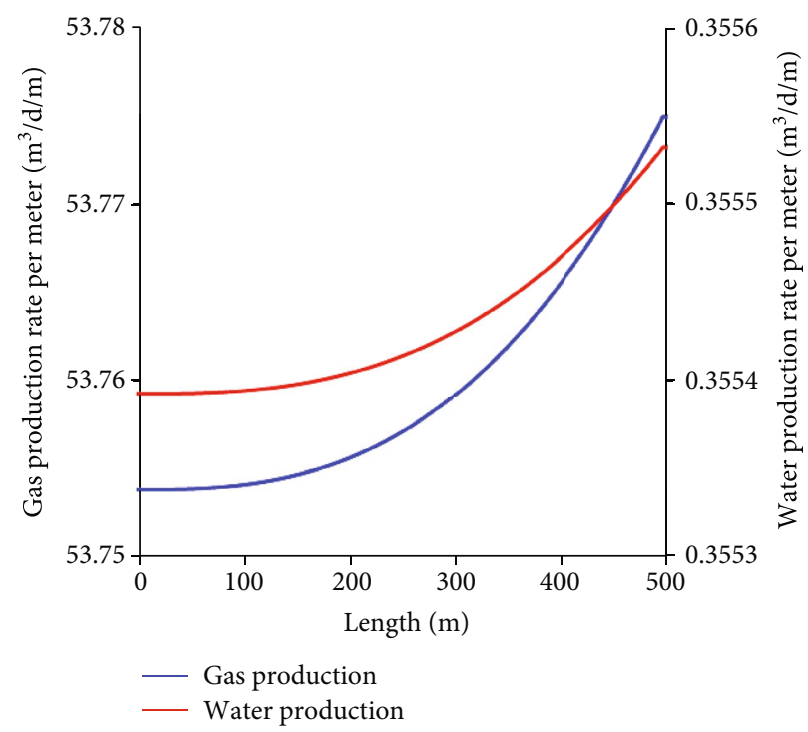

(a) Gas and water inflow profile

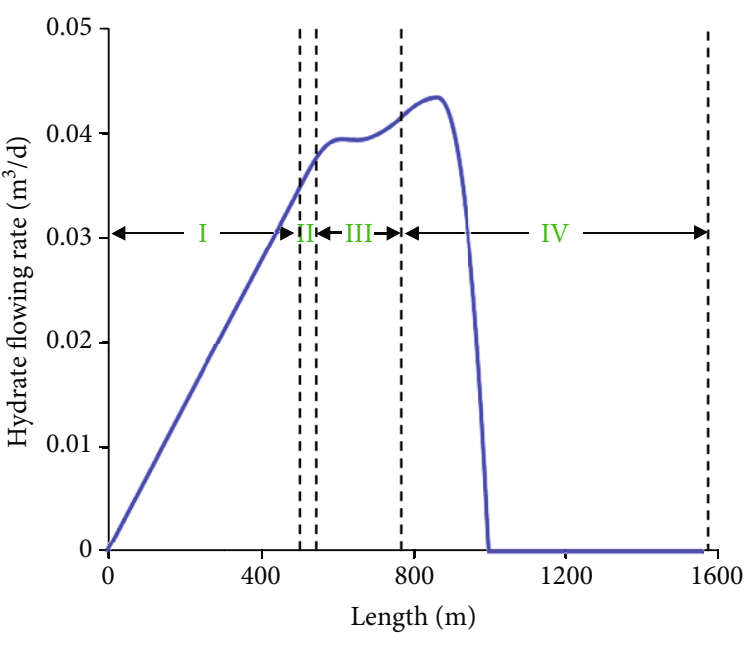

(b) Hydrate flow rate distribution in the wellbore

Figure 7: Gas and water inflow profile and hydrate flow rate distribution in the wellbore.

wellbore temperature distributions corresponding to the three schemes is only reflected in the horizontal and deflecting sections; the lower the environment temperature is, the lower the fluid temperature will be in a horizontal section. For the deflecting section, the fluid temperature in the wellbore will rapidly increase because of the increase in the environmental temperature. The temperatures in the wellbore for the three schemes are gradually approaching each other. According to Figure 9(b), the lower the temperature is in the horizontal section, the faster the hydrate generation rate will be, and the maximum hydrate flow rates corresponding to environment temperatures of $5.4^{\circ} \mathrm{C}, 6.4^{\circ} \mathrm{C}$, and $7.4^{\circ} \mathrm{C}$ are $0.036,0.044$, and $0.048 \mathrm{~m}^{3} / \mathrm{d}$, respectively, which means that a lower wellbore temperature will lead to a faster hydrate generation rate; however, because the hydrate decomposition rate is much faster than its generation rate, the hydrate will rapidly decompose when the temperature in the wellbore is 


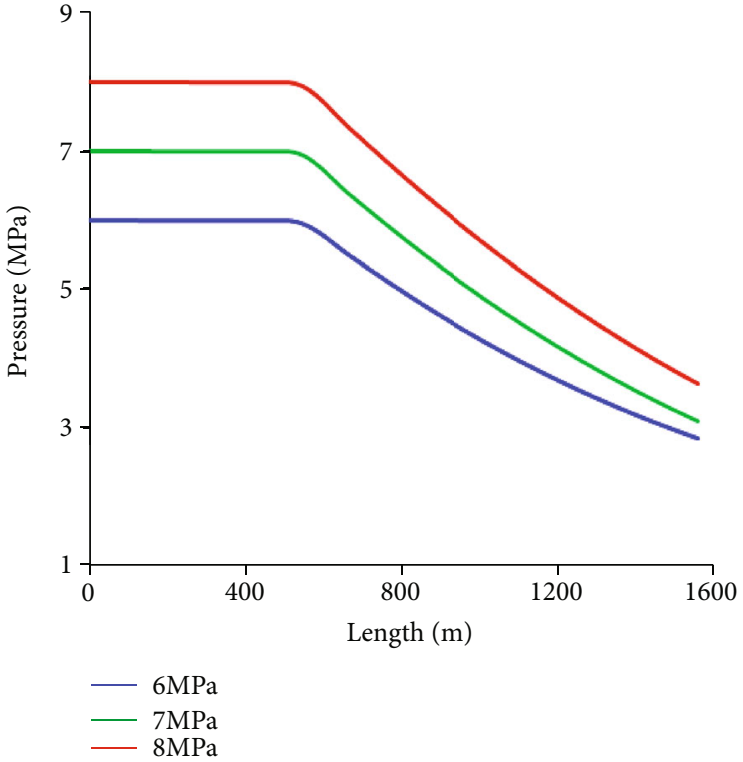

(a) Comparison of wellbore pressure

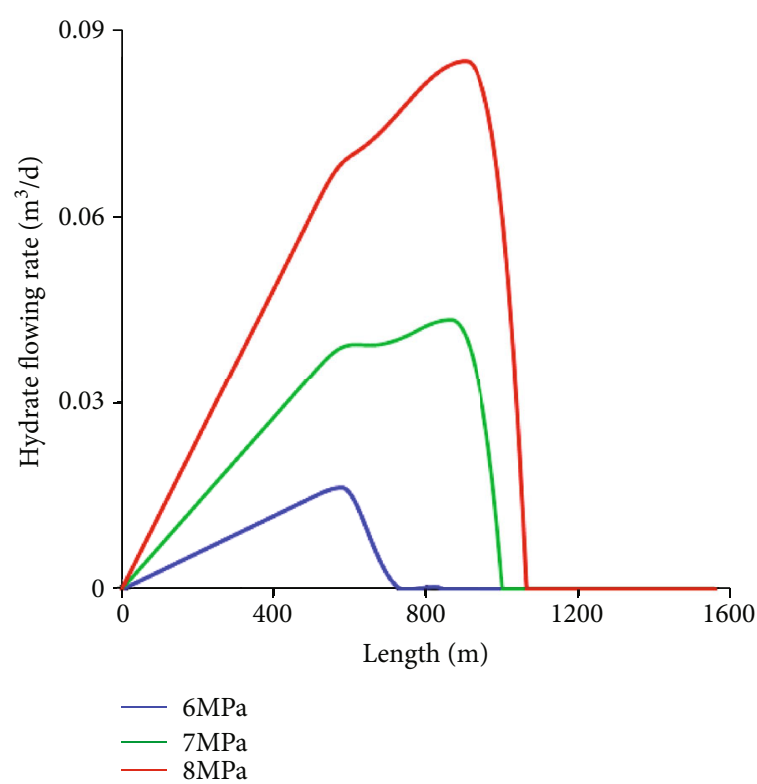

(c) Comparison of hydrate flow rate

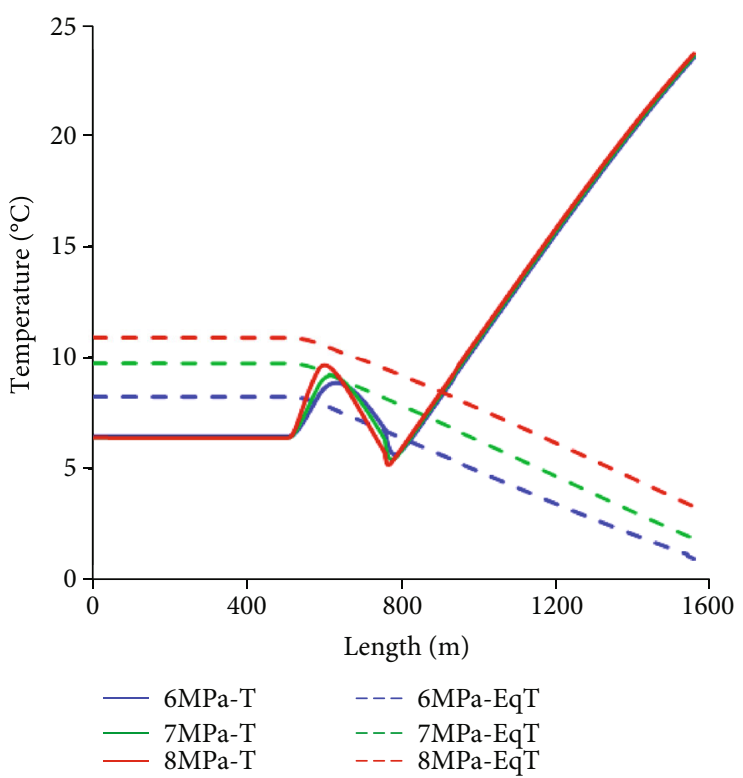

(b) Comparison of wellbore temperature

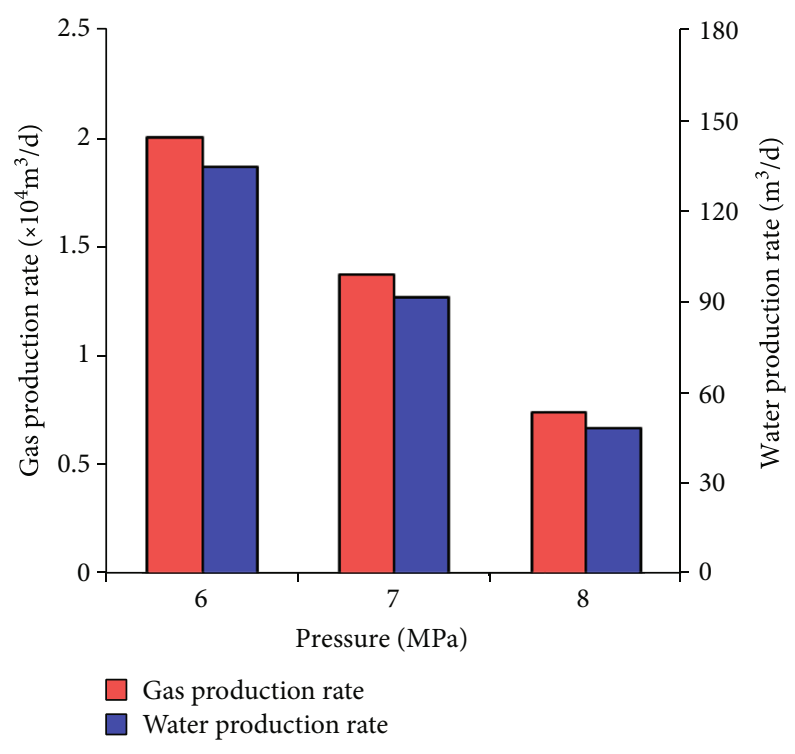

(d) Comparison of gas and water outputs

FIgURE 8: Comparison of each wellbore parameter under different toe-end pressures.

higher than the hydrate phase equilibrium temperature, and the differences among the hydrate generation areas in the three schemes are slight.

4.2.3. Influence of Gas Output. To investigate the influence of the gas output on hydrate generation in the wellbore, assuming the toe-end pressure and environment temperature as $7 \mathrm{MPa}$ and $6.4^{\circ} \mathrm{C}$, respectively, the gas output index is set as $0.5 \times 10^{-4} \mathrm{~kg} /(\mathrm{MPa} \cdot \mathrm{m} \cdot \mathrm{s}), \quad 1 \times 10^{-4} \mathrm{~kg} /(\mathrm{MPa} \cdot \mathrm{m} \cdot \mathrm{s})$, and $1.5 \times 10^{-4} \mathrm{~kg} /(\mathrm{MPa} \cdot \mathrm{m} \cdot \mathrm{s})$ for the three schemes, respectively. Figure 10 shows a comparison diagram of the onway pressure, temperature, hydrate flow rate, and total gas and water outputs under different gas outputs. It can be seen from the figure that, because the frictional resistance of the wellbore is small, the difference among the fluid pressures in the horizontal wellbore under different gas outputs is slight. For the vertical wellbore, the gas holdup increases because, owing to a large gas output, the density of the gaswater mixture decreases, and thus, the differential pressure in the vertical section under a large gas output is small. According to Figure 10(b), although the difference among the fluid pressures in the wellbore under different gas outputs is slight, the pressures in the vertical wellbore under different gas outputs are different, and the corresponding phase 


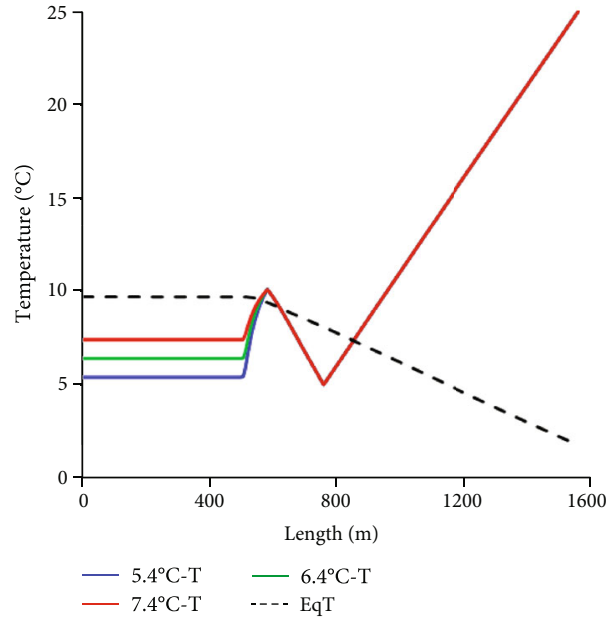

(a) Comparison of the wellbore temperature

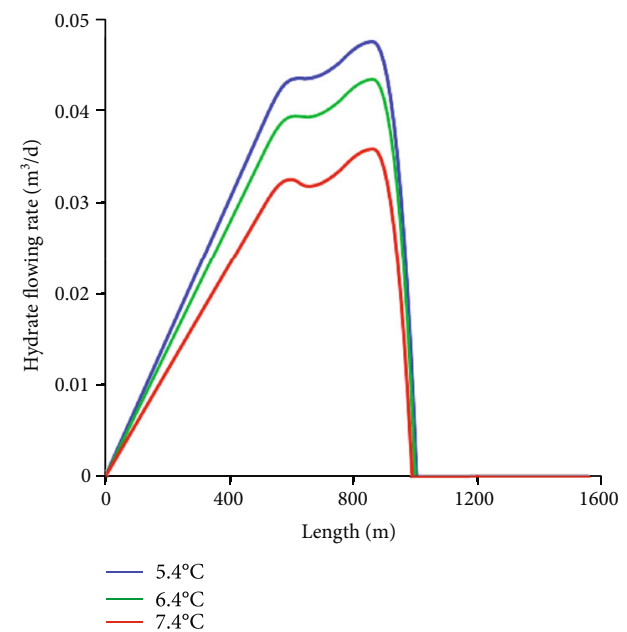

(b) Comparison of the hydrate flow rate

Figure 9: Comparison of wellbore temperature and hydrate flow rate under different horizontal well environment temperatures.

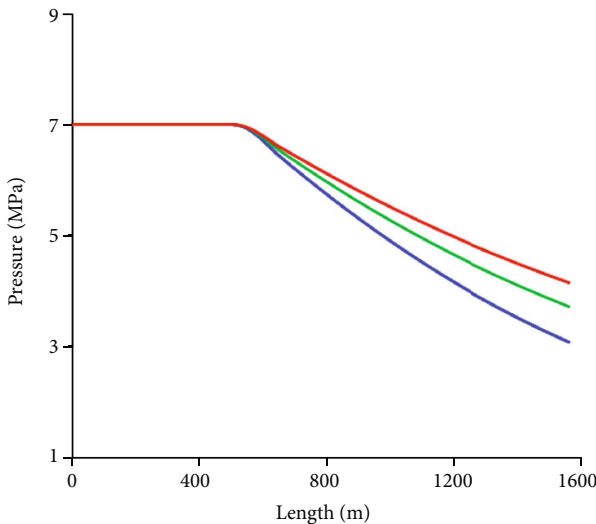

- $0.5 \times 10^{-4} \mathrm{~kg} /(\mathrm{MPa} \cdot \mathrm{m} \cdot \mathrm{s})$

$-1.0 \times 10^{-4} \mathrm{~kg} /(\mathrm{MPa} \cdot \mathrm{m} \cdot \mathrm{s})$

$1.5 \times 10^{-4} \mathrm{~kg} /(\mathrm{MPa} \cdot \mathrm{m} \cdot \mathrm{s})$

(a) Comparison of the wellbore pressure

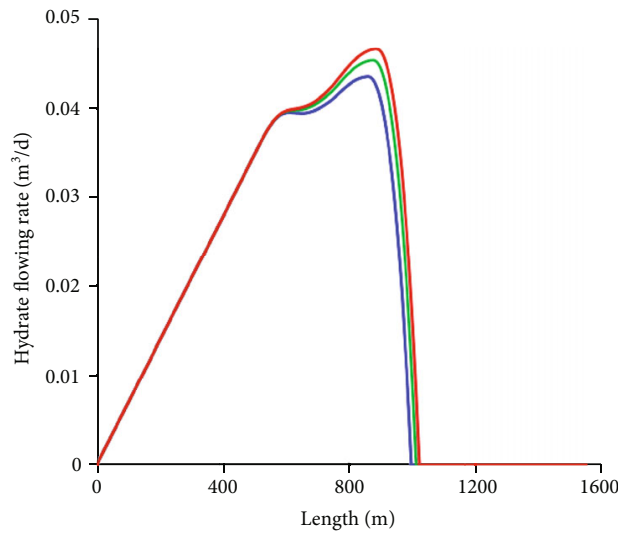

$0.5 \times 10^{-4} \mathrm{~kg} /(\mathrm{MPa} \cdot \mathrm{m} \cdot \mathrm{s})$

$-1.0 \times 10^{-4} \mathrm{~kg} /(\mathrm{MPa} \cdot \mathrm{m} \cdot \mathrm{s})$

$1.5 \times 10^{-4} \mathrm{~kg} /(\mathrm{MPa} \cdot \mathrm{m} \cdot \mathrm{s})$

(c) Comparison of the hydrate flow rate

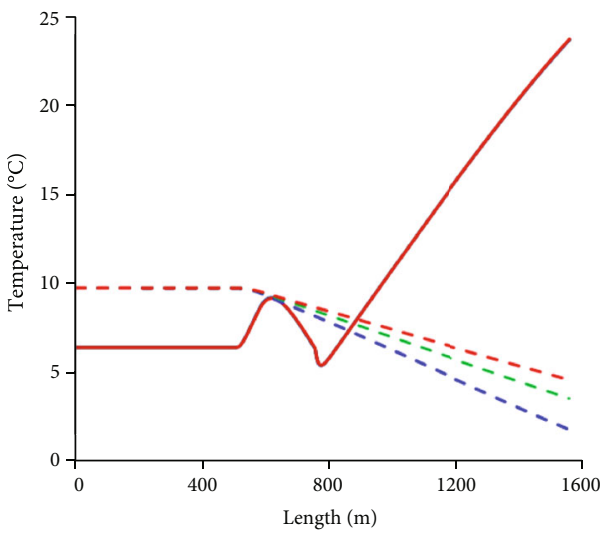

- $0.5 \times 10^{-4} \mathrm{~kg} /(\mathrm{MPa} \cdot \mathrm{m} \cdot \mathrm{s})-\mathrm{T}$

$-1.0 \times 10^{-4} \mathrm{~kg} /(\mathrm{MPa} \cdot \mathrm{m} \cdot \mathrm{s})-\mathrm{T}$

$1.5 \times 10^{-4} \mathrm{~kg} /(\mathrm{MPa} \cdot \mathrm{m} \cdot \mathrm{s})-\mathrm{T}$

$0.5 \times 10^{-4} \mathrm{~kg} /(\mathrm{MPa} \cdot \mathrm{m} \cdot \mathrm{s})-\mathrm{EqT}$

- $1.0 \times 10^{-4} \mathrm{~kg} /(\mathrm{MPa} \cdot \mathrm{m} \cdot \mathrm{s})-\mathrm{EqT}$

(b) Comparison of the wellbore temperature

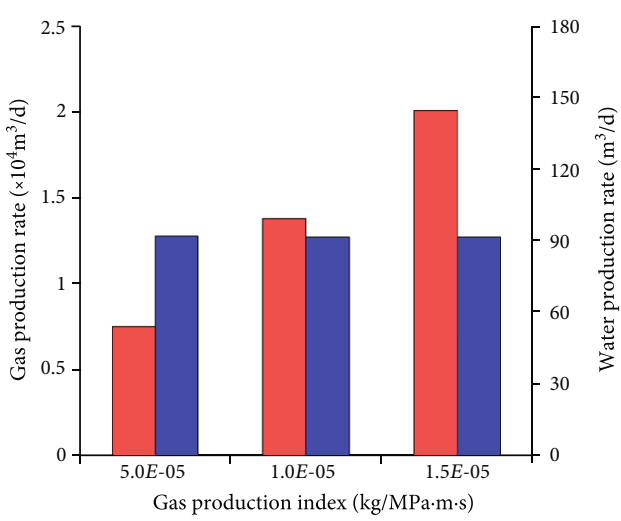

Gas production rate

Water production rate

(d) Comparison of the gas and water outputs

FIGURE 10: Comparison of each wellbore parameter under different gas output indexes. 
equilibrium pressures also have some differences, i.e., the larger the gas output, the higher the equilibrium temperature of the corresponding vertical section will be. At the same time, according to Figure 10(c), the higher gas output corresponds to a larger hydrate generation area and hydrate generation amount, although the differences among the three schemes are generally small. Because only the gas production index is changed, and according to Figure $10(\mathrm{~d})$, the liquid outputs of the three schemes are basically the same; the gas outputs increase as the gas output indexes increase.

\section{Conclusions}

In this study, a multiphase pipe flow of a horizontal well was combined with natural gas hydrate generation and a decomposition dynamics model to establish a set of gas-liquid-solid three-phase flow models of a horizontal well when considering the phase transition in the wellbore. Based on this model, the temperature and pressure distribution and hydrate secondary generation rule are analyzed in the wellbore. The main conclusions obtained are as follows:

(1) The viscosities of gas and water are low, the pressure loss in the horizontal section caused by frictional resistance is small, and the fluid pressure in the horizontal section is almost the same. If the toe-end pressure is higher than the equilibrium pressure of the hydrate phase, the hydrate generation condition will be met within the entire horizontal section

(2) The fluid pressure loss in a wellbore is mainly consumed in the fluid lifting of the deflecting section and the vertical section after it reaches the deflecting section; when the environment temperature changes, the changing trends of wellbore fluid temperature and environment temperature are the same. Because the temperatures of the sea-bottom and the subbottom formation are relatively low, the horizontal wellbore area mainly concentrates on the horizontal section of the horizontal well, the sea-bottom formation section, and the subsea area if the hydrate generation condition is met in a horizontal wellbore

(3) For the case described herein, the fastest hydrate flow in the wellbore is $0.044 \mathrm{~m}^{3} / \mathrm{d}$. If the generated hydrate has certain amounts of pipe wall deposition, it may block the wellbore and cause a decrease in its effective diameter. Heating and other measures should be adopted to prevent hydrate generation in the wellbore to ensure a smooth production

(4) Pressure in the wellbore has a significant influence on the secondary hydrate generation. In addition, the hydrate generation area and flow amount in the wellbore increase as the toe-end pressure increases, and thus, to prevent a hydrate generation and wellbore blockage, the pressure in the wellbore should be closely monitored during the actual development of a hydrate reservoir. A lower wellbore temperature and higher gas output index will lead to a greater amount of hydrate generated, and the influences of these two factors on the secondary hydrate generation will be much smaller than the influence of the wellbore pressure

The three-phase mass variable mathematical model of a horizontal well considers the hydrate phase transition, which is a stable state model. During the depressurization development process of a natural gas hydrate reservoir, the pressure, temperature, and gas and water indexes of the near-wellbore formation are continuously changing as the development progresses. At different development stages, the gas-water flow state and hydrate secondary generation situation in the wellbore are different, and the influence of the hydrate generated in the wellbore on the reservoir development is the study category of the instable model. Subsequent studies need to couple the established stable state model with a natural gas hydrate reservoir depressurization development model and utilize the coupled instability model to confirm the above studies.

\section{Data Availability}

The data used to support the findings of this study are available from the corresponding author upon request.

\section{Conflicts of Interest}

The authors declare that there are no conflicts of interest regarding the publication of this paper.

\section{Acknowledgments}

This work was financially supported by the National Natural Science Foundation of China (Grant No. 51804324), the National Science Foundation for Distinguished Young Scholars of China (Grant No. 51625403), the Major Scientific and Technological Projects of CNPC (ZD2019-184-002), Natural Science Foundation of Shandong Province (Grant No. ZR2017QEE008, ZR2018BEE004), the Indigenous Innovation Program of Qingdao (Grant No. 16-5-46-jch), and the Fundamental Research Funds for the Central Universities (Grant No. 18CX02169A).

\section{References}

[1] Z. R. Chong, S. H. B. Yang, P. Babu, P. Linga, and X. S. Li, "Review of natural gas hydrates as an energy resource: prospects and challenges," Applied Energy, vol. 162, pp. 16331652, 2016.

[2] J. B. Klauda and S. I. Sandler, "Global distribution of methane hydrate in ocean sediment," Energy \& Fuels, vol. 19, no. 2, pp. 459-470, 2005.

[3] A. Demirbas, "Methane hydrates as potential energy resource: part 2 - methane production processes from gas hydrates," Energy Conversion \& Management, vol. 51, no. 7, pp. 15621571, 2010.

[4] G. J. Moridis, T. S. Collett, R. Boswell et al., "Toward production from gas hydrates: current status, assessment of resources, and simulation-based evaluation of technology and potential," 
SPE Reservoir Evaluation \& Engineering, vol. 12, pp. 745-771, 2009.

[5] L. L. Liu, X. B. Lu, X. H. Zhang, C. L. Liu, and B. Du, "Numerical simulations for analyzing deformation characteristics of hydrate-bearing sediments during depressurization," Advances in Geo-Energy Research, vol. 1, no. 3, pp. 135-147, 2017.

[6] L. Huang, Z. Su, N. Y. Wu, and J. W. Chen, "Analysis on geologic conditions affecting the performance of gas production from hydrate deposits," Marine and Petroleum Geology, vol. 77, pp. 19-29, 2017.

[7] X. S. Li, C. G. Xu, Y. Zhang, X. K. Ruan, G. Li, and Y. Wang, "Investigation into gas production from natural gas hydrate: a review," Applied Energy, vol. 172, pp. 286-322, 2016.

[8] G. J. Moridis, T. S. Collett, S. R. Dallimore, T. Satoh, S. Hancock, and B. Weatherill, "Numerical simulation studies of gas production scenarios from hydrate accumulations at the Mallik Site, Mackenzie Delta, Canada," in Presented at 4th International Conference on Gas Hydrates, Yokohama Symposia, Yokohama, Japan, May 2002.

[9] Y. Liu, J. Hou, H. Zhao, X. Liu, and Z. Xia, “A method to recover natural gas hydrates with geothermal energy conveyed by CO2," Energy, vol. 144, pp. 265-278, 2018.

[10] J. Sun, L. Zhang, F. Ning et al., "Production potential and stability of hydrate-bearing sediments at the site GMGS3-W19 in the South China Sea: a preliminary feasibility study," Marine and Petroleum Geology, vol. 86, pp. 447-473, 2017.

[11] Y. Liu, J. Hou, H. Zhao, X. Liu, and Z. Xia, "Numerical simulation of simultaneous exploitation of geothermal energy and natural gas hydrates by water injection into a geothermal heat exchange well," Renewable and Sustainable Energy Reviews, vol. 109, pp. 467-481, 2019.

[12] X. Zang, D. Liang, and N. Wu, "Investigation of $\mathrm{CO}_{2}$ separation from synthesis $\mathrm{CO}_{2} / \mathrm{CH}_{4}$ mixture utilizing tetra-n-butyl ammonium bromide semi-hydrate," Canadian Journal of Chemical Engineering, vol. 94, no. 9, pp. 1792-1800, 2016.

[13] M. Pooladi-Darvish, "Gas production from hydrate reservoirs and its modeling," Journal of Petroleum Technology, vol. 56, pp. 65-71, 2004.

[14] J. Hou, E. Zhao, Y. Liu et al., "Pressure-transient behavior in class III hydrate reservoirs," Energy, vol. 170, pp. 391-402, 2019.

[15] G. Moridis, "Numerical studies of gas production from class 2 and class 3 hydrate accumulations at the Mallik Site, Mackenzie Delta, Canada," SPE Reservoir Evaluation \& Engineering, vol. 7, pp. 175-183, 2004.

[16] E. M. Myshakin, M. Gaddipati, K. Rose, and B. J. Anderson, "Numerical simulations of depressurization-induced gas production from gas hydrate reservoirs at the Walker Ridge 313 site, northern Gulf of Mexico," Marine \& Petroleum Geology, vol. 34, no. 1, pp. 169-185, 2012.

[17] E. M. Myshakin, T. Ajayi, B. J. Anderson, Y. Seol, and R. Boswell, "Numerical simulations of depressurizationinduced gas production from gas hydrates using 3-D heterogeneous models of L-Pad, Prudhoe Bay Unit, North Slope Alaska," Journal of Natural Gas Science \& Engineering, vol. 35, pp. 1336-1352, 2016.

[18] X. Ruan, Y. Song, J. Zhao, H. Liang, M. Yang, and Y. Li, "Numerical simulation of methane production from hydrates induced by different depressurizing approaches," Energies, vol. 5, no. 2, pp. 438-458, 2012.
[19] M. Gaddipati and B. Anderson, "3D reservoir modeling of depressurization-induced gas production from gas hydrate reservoirs at the walker ridge site, Northern Gulf of Mexico," Critical Care Medicine, vol. 30, pp. 290-296, 2012.

[20] G. A. Grasso, E. D. Sloan, C. A. Koh, and A. K. Sum, "Hydrate deposition mechanisms on pipe walls," in Presented at the Offshore Technology Conference, Houston, TX, USA, May 2014.

[21] S. V. Joshi, G. A. Grasso, P. G. Lafond et al., "Experimental flowloop investigations of gas hydrate formation in high water cut systems," Chemical Engineering Science, vol. 97, pp. 198209, 2013.

[22] V. Andersson and J. S. Gudmundsson, "Flow properties of hydrate-in-water slurries," Annals of the New York Academy of Science, vol. 912, no. 1, pp. 322-329, 2000.

[23] L. Ding, B. Shi, X. Lv et al., "Investigation of natural gas hydrate slurry flow properties and flow patterns using a high pressure flow loop," Chemical Engineering Science, vol. 146, pp. 199-206, 2016.

[24] J. W. Nicholas, L. E. Dieker, E. D. Sloan, and C. A. Koh, “Assessing the feasibility of hydrate deposition on pipeline walls-adhesion force measurements of clathrate hydrate particles on carbon steel," Journal of Colloid and Interface Science, vol. 331, no. 2, pp. 322-328, 2009.

[25] E. Jassim, M. A. Abdi, and Y. Muzychka, "A new approach to investigate hydrate deposition in gas-dominated flowlines," Journal of Natural Gas Science and Engineering, vol. 2, no. 4, pp. 163-177, 2010.

[26] J. W. Nicholas, C. A. Koh, E. D. Sloan, L. Nuebling, H. He, and B. Horn, "Measuring hydrate/ice deposition in a flow loop from dissolved water in live liquid condensate," AICHE Journal, vol. 55, no. 7, pp. 1882-1888, 2009.

[27] Z. Wang, Y. Zhao, B. Sun, L. Chen, J. Zhang, and X. Wang, "Modeling of hydrate blockage in gas-dominated systems," Energy \& Fuels, vol. 30, no. 6, pp. 4653-4666, 2016.

[28] Z. Wang, J. Zhang, B. Sun, L. Chen, Y. Zhao, and W. Fu, "A new hydrate deposition prediction model for gas-dominated systems with free water," Chemical Engineering Science, vol. 163, pp. 145-154, 2017.

[29] Z. Wang, J. Zhang, L. Chen et al., "Modeling of hydrate layer growth in horizontal gas-dominated pipelines with free water," Journal of Natural Gas Science and Engineering, vol. 50, pp. 364-373, 2018.

[30] H. Zambrano, L. D. G. Sigalotti, J. Klapp, F. Peña-Polo, and A. Bencomo, "Heavy oil slurry transportation through horizontal pipelines: experiments and CFD simulations," International Journal of Multiphase Flow, vol. 91, pp. 130-141, 2017.

[31] N. Wang, B. Sun, Z. Wang, J. Wang, and C. Yang, "Numerical simulation of two phase flow in wellbores by means of drift flux model and pressure based method," Journal of Natural Gas Science and Engineering, vol. 36, pp. 811-823, 2016.

[32] V. Oballa and L. Buchanan, Flexible Wellbore Model Coupled to Thermal Reservoir Simulator, Presented at World Heavy Oil congress, Puerto La cruz, Venezuela, 2009.

[33] H. C. Kim, P. R. Bishnoi, R. A. Heidemann, and S. S. H. Rizvi, "Kinetics of methane hydrate decomposition," Chemical Engineering Science, vol. 42, no. 7, pp. 1645-1653, 1987.

[34] A. Vysniauskas and P. R. Bishnoi, "A kinetic study of methane hydrate formation," Chemical Engineering Science, vol. 38, no. 7, pp. 1061-1072, 1983. 
[35] G. J. Moridis, "Numerical studies of gas production from methane hydrates," SPEJ, vol. 8, pp. 359-370, 2002.

[36] Y. Jin, "Numerical simulation of two-phase gas-liquid flow in pipes," Ph.D. Thesis, Southwest Petroleum University, 2005.

[37] Z. Wang, Y. Zhao, J. Zhang, S. Pan, J. Yu, and B. Sun, "Flow assurance during deepwater gas well testing: hydrate blockage prediction and prevention," Journal of Petroleum Science and Engineering, vol. 163, pp. 211-216, 2018.

[38] G. Li, G. J. Moridis, K. Zhang, and X. S. Li, "The use of huff and puff method in a single horizontal well in gas production from marine gas hydrate deposits in the Shenhu Area of South China Sea," Journal of Petroleum Science and Engineering, vol. 77, no. 1, pp. 49-68, 2011.

[39] K. Zhang, G. J. Moridis, N. Y. Wu, X. S. Li, and M. T. Reagan, "Evaluation of Alternative Horizontal Well Designs for Gas Production From Hydrate deposits in the Shenhu Area, South China Sea," in International Oil and Gas Conference and Exhibition in China, Beijing China, 2010.

[40] C. L. Liu, Q. G. Meng, G. W. Hu et al., "Characterization of hydrate-bearing sediments recovered from the Shenhu area of the South China Sea," Interpretation-A Journal of Subsurface Characterization, vol. 5, pp. SM13-SM23, 2017.

[41] Z. Su, G. J. Moridis, K. Zhang, R. Yang, and N. Y. Wu, "SS Gas Hydrate: Numerical investigation of gas production strategy for the hydrate deposits in the Shenhu area," in Offshore Technology Conference, Houston, TX, USA, 2010.

[42] Y. Liu, Y. Bai, Z. Xia, and J. Hou, "Parameter optimization of depressurization-to-hot-water-flooding in heterogeneous hydrate bearing layers based on the particle swarm optimization algorithm," Journal of Natural Gas Science and Engineering, vol. 53, pp. 403-415, 2018. 